\title{
Motor gerador ciclo diesel sob cinco proporções de biodiesel com óleo diesel
}

\author{
Marcelo J. da Silva ${ }^{1}$, Samuel N. M. de Souza ${ }^{2}$, Abel A. Souza ${ }^{2}$, \\ Gislaine I. Martins ${ }^{2} \&$ Deonir Secco ${ }^{2}$
}

\begin{abstract}
RESU M 0
0 estudo de fontes alternativas de energia ao óleo diesel mineral, como o biodiesel, com origem renovável, é importante para o meio-ambiente e diversificação da matriz energética. N este estudo foram levantados o consumo específico de combustível, o valor calórico do combustível e a eficiência do conjunto motor gerador da marca BRAN CO em função de cargas resistivas, sob as seguintes proporções volumétricas entre o óleo diesel mineral com biodiesel: 0\% (B0), 20\% (B20), 40\% (B40), 60\% (B60) e $100 \%$ de biodiesel (B100). Para o ensaio utilizou-se motor de 7,36 kW, com gerador elétrico acoplado de $5,5 \mathrm{~kW}$. As cargas utilizadas, $0,5 \mathrm{~kW} ; 1,0 \mathrm{~kW} ; 1,5 \mathrm{~kW}$ e 2,0 kW foram elevadas até $5,0 \mathrm{~kW}$, oriundas de um dinamômetro de cargas resistentes. Assim, o desempenho do conjunto para cargas abaixo de 1,5 kW mostrou-se menor, pelo maior consumo específico de combustível (CEC), e redução na eficiência do conjunto motor gerador para a faixa de potência. Para as proporções de biodiesel B40, B60 e B100 os resultados descreveram redução no valor calórico e aumento do CEC. Portanto, realizando comparação das proporções de biodiesel com o óleo diesel, a proporção B20 substitui parcialmente o óleo diesel, sem perdas significativas do desempenho do motor gerador.
\end{abstract}

Palavras-chave: consumo específico de combustível, valor calórico, eficiência do conjunto motor gerador

\section{Engine-generator diesel cycle under five proportions of biodiesel and diesel}

\begin{abstract}
The study of mineral diesel alternatives, such as biodiesel, a renewable fuel, is important for the environment and to diversify energy sources. This study evaluated an engine-generator BRAN CO brand. Specific fuel consumption, calorific value and the overall efficiency as a function of the system load was measured, using diesel oil and biodiesel blends. The biodiesel proportions in the composition were $0 \%$ (B0), 20\% (B20), 40\% (B40), 60\% (B60), and 100\% (B100). The engine that was used during the test has a power of $7.36 \mathrm{~kW}$, and the electric generator was $5.5 \mathrm{~kW}$. The group was submitted to resistive loading, in the range: $0.5 \mathrm{~kW}, 1.0 \mathrm{~kW}, 1.5 \mathrm{~kW}$; growing up to $5.0 \mathrm{~kW}$. The results have shown that, when operating at lower loads (less than $1.5 \mathrm{~kW}$ ), the engine-generator performance decreased, while the specific consumption increased, leading to an efficiency reduction. The biodiesel proportions B 40, B60 and B100 described reduction in caloric value and increased the specific fuel consumption. Therefore, comparing the proportions of biodiesel with diesel oil, the proportion B20 replaced diesel oil without significant losses in engine-generator performance.
\end{abstract}

Key words: specific fuel consumption, calorific value, overall efficiency

\footnotetext{
${ }^{1}$ FEAGRI/U N ICAMP, Av. Candido Rondon, 501, Cidade Universitária Zeferino Vaz, Barão Geraldo, CEP 13083-875, Campinas, SP. Fone: (19) $8228-6807$. E-mail. marcelo js07@hotmail.com

${ }^{2}$ Centro de Ciências Exatas e Tecnológicas, Engenharia Agrícola, Universidade Estadual do O este do Paraná, Rua Universitária, 2069, Bairro Universitário, CEP 85814-110, C.P. 711, Cascavel, PR. Fone: (45) 3220-3000. E-mail: samuel.souza@unioeste.br; abel.sza@hotmail.com; iastiaque@yahoo.com.br; deonir@unioeste.br
} 


\section{INTRODUÇÃO}

O biodiesel é fonte de energia alternativa e renovável além de substituto principalmente do óleo Diesel, combustível com origem não renovável. Os principais materiais utilizados para a produção do biodiesel são óleos vegetais (óleo de soja, girassol, canola, mamona, dendê) e gorduras animais, como sebo bovino e gordura de frango e ainda o uso de óleo residual de frituras.

$\mathrm{Na}$ produção do biodiesel a principal fase é a transesterificação. Segundo Knothe et al. (2006), a transesterificação é o único processo pelo qual se obtém os produtos comumente denominados biodiesel (esteres etílicos e metílicos). No processo o material de origem animal (triacilglicerois) reage especificamente com álcool (etanol ou metanol), na presença de um catalisador, resultando o glicerol (subproduto) e o éster metílico, que é o biodiesel, refinado nos processos de separação de fases e purificação dos ésteres.

O biodiesel pode ser utilizado em motores de quatro tempos ciclo diesel, sem maiores complicações. No entanto, o uso do biodiesel pelos motores pode modificar as características do óleo lubrificante, como descrito por Corrêa et al. (2011) que, ao utilizar biodiesel de sebo na proporção B5 em motor ciclo diesel, verificaram alteração das características do óleo lubrificante após $400 \mathrm{~h}$ de funcionamento, sendo a deterioração relacionada à possibilidade da presença de contaminantes, como a água, sílica e resíduos da combustão e o próprio combustível. Com a degradação do óleo lubrificante os desgastes pela abrasão dos componentes móveis do motor são maiores. Deste modo, o dimensionamento e o projeto de motores para biodiesel devem considerar as condições de operação com exposição a danos no motor, como a deposição de carvão sob injetores, cabeçote e pistões tal como, também, a deterioração precoce do óleo de lubrificação.

Porém, existem diferenças para as características físicoquímicas dos biocombustíveis, como descrito em Costa Neto et al. (2000) para óleo diesel e cinco biodieseis produzidos a partir de fontes oleaginosas (babaçu, dendê, algodão e pequi), através de análises para o poder calorífico $\left(\mathrm{MJ} \mathrm{kg}^{-1}\right)$, ponto de névoa $\left({ }^{\circ} \mathrm{C}\right)$, densidade $\left(\mathrm{g} \mathrm{cm}^{-1}\right)$, viscosidade $(\mathrm{cSt})$, ponto de fluidez $\left({ }^{\circ} \mathrm{C}\right)$, teor de cinzas $(\%)$, e teor de enxofre $(\%)$.

Todavia, a produção e o consumo de biodiesel da gordura de frango podem ser uma alternativa energética muito atrativa em regiões com alta produção de aves para abate, como nas Regiões Oeste do Paraná e Oeste de Santa Catarina. Nesses locais existem agroindústrias ligadas ao sistema de cooperados para criação de aves, contribuindo para o "status" do Brasil como $3^{\circ}$ maior produtor de aves de corte do mundo (IBGE, 2010). A produção de biodiesel à base de gordura residual da agroindústria de processamento de aves, uma fonte alternativa à produção de energia, que pode ser ofertada a um custo menor, comparada a outras fontes de produção de biodiesel. Segundo Kulkarni \& Dalai (2006) este tipo de material é considerado, do mesmo modo que para óleo de frituras, reconhecido como resíduo, podendo ser adquirido com baixo custo e alta disponibilidade, a partir das agroindústrias. O biodiesel produzido a partir da gordura de frango também pode trazer benefícios para o meio-ambiente, pela transformação do subproduto da agroindústria em biocombustível, caracterizado como fonte de energia renovável.

Em estudo realizado por Gomes et al. (2008) estimou-se o potencial de produção de biodiesel da gordura de frango, de acordo com o número de aves abatidas em cinco Cooperativas localizadas no Oeste do Paraná; verificou-se, então, que são abatidas 1.140.000 aves por dia ou 300.960.000 aves por ano, o que gera uma produção diária de $77.292,00 \mathrm{~kg}$ de gordura de frango ou anual de $20.405 .088,00 \mathrm{~kg}$. Segundo os autores, que consideraram a conversão de $95 \%$ gordura de frango em biodiesel, o potencial levantado de produção de biodiesel nas cinco cooperativas é de $73.959,13 \mathrm{~kg} \mathrm{dia}^{-1}$ ou $19.525 .209,00$ $\mathrm{kg}$ ano $^{-1}$ de biodiesel.

Segundo Dabdoub et al. (2009) a utilização de "novas matérias-primas" na produção do biodiesel tem esbarrado no fato de que muitos óleos ou gorduras vegetais e animais não possuem composição adequada para permitir que o produto da sua transesterificação se enquadre nas especificações de qualidade exigidas aos combustíveis. Os parâmetros do biodiesel biocombustível foram definidos por meio de uma resolução n.7 da Agência Nacional do Petróleo, Gás Natural e Biocombustíveis (ANP), publicada no ano de 2008.

$\mathrm{O}$ biodiesel da gordura de frango utilizado em motores de combustão interna ciclo diesel, pode ser empregado com diferentes proporções volumétricas de óleo diesel, fato que, sem dúvida, também ensejou, neste estudo, o intuito de se analisar o desempenho de conjunto motor gerador da marca Branco, com potência de 7,36 kW (10 cv) e gerador de 5,5 kW utilizando-se quatro proporções volumétricas de biodiesel da gordura de frango, comparadas às do óleo diesel mineral.

\section{Material E MÉtodos}

Neste estudo se utilizou um motor gerador ciclo diesel, modelo BD $6500 \mathrm{CF}$ de 7,36 kW $(10 \mathrm{cv})$ de potência com 5,5 kVA/5,0 kW de potência nominal, com tensão de saída de 120/ $240 \mathrm{~V}$ monofásico. O biodiesel utilizado foi adquirido junto a uma unidade produtora que trabalha em processo descontinuo num sistema de batelada, localizada em Cascavel, PR. A capacidade nominal de produção da unidade é de $900 \mathrm{~L}$ por turno de $8 \mathrm{~h}$.

$\mathrm{O}$ biodiesel fornecido pela unidade produtora para este estudo foi produzido a partir de gorduras residuais (subprodutos ricos em lipídios) provenientes de agroindústrias de abate de aves na região, produzido pela rota metílica e com catálise alcalina, em que o hidróxido de sódio foi empregado para acelerar a reação. A matéria-prima foi avaliada quanto ao teor de acidez expresso em ácido oléico, ficando abaixo de 3\%; assim, o catalisador (que depende deste parâmetro) foi utilizado sempre na mesma quantidade. A quantidade de metanol empregada no processo de produção foi $20 \%$ do volume total.

O combustível utilizado neste estudo foi composto de uma mistura volumétrica entre o biodiesel e o óleo diesel mineral. As proporções do biodiesel na composição do combustível foram: $0 \%$ (B0), 20\% (B20), 40\% (B40), 60\% (B60) e 100\% de biodiesel (B100). Para medir a massa de combustível consumida foi utilizado um tanque externo de armazenamento, o qual foi 
pesado em uma balança de precisão, obtendo-se o consumo de combustível durante os testes com conjunto motor gerador. O tempo de realização de cada teste foi contabilizado com um cronômetro digital obtendo-se, deste modo, o consumo horário de combustível (fluxo de massa). A Eq. 1 mostra o cálculo do consumo de combustível realizado em cada um dos testes de desempenho do conjunto.

$$
\dot{\mathrm{M}}=\left(\frac{(\mathrm{Mr}+\mathrm{Mi})-(\mathrm{Mr}+\mathrm{Mf})}{\mathrm{t}}\right)
$$

em que:

M - consumo horário de combustível, $\mathrm{kg} \mathrm{s}^{-1}$

$\mathrm{Mr}$ - massa do recipiente que armazena o combustível, $\mathrm{kg}$

Mi - massa inicial de combustível, $\mathrm{kg}$

Mf - massa final de combustível, $\mathrm{kg}$

t - tempo do ensaio, $\mathrm{s}$

A simulação da carga no gerador foi realizada por meio de um banco de resistores cujas potências são controladas através de chaves de um painel elétrico. As cargas nominais adotadas se iniciaram a partir de cargas menores, aplicando-se: 0,$5 ; 1,0$; 1,$5 ; 2,0 ; 2,5 ; 3,0 ; 3,5 ; 4,0 ; 4,5$ e 5,0 kW. As cargas adotadas foram as mesmas empregadas para efeito de comparação das diferentes misturas volumétricas entre o óleo diesel mineral e o biodiesel.

Para avaliação do desempenho do conjunto tomou-se como base o consumo específico (CEC) e a eficiência de conversão $(\eta)$ em energia elétrica no conjunto motor gerador. O CEC foi determinado em função da variação da carga do motor gerador operando com o óleo diesel mineral, ou seja, B0, e operando com as proporções B20, B40, B60 e B100 de biodiesel.

$$
\mathrm{CEC}=\left(\frac{3,6 \cdot 10^{3} \times \mathrm{M}}{\mathrm{V} \times \mathrm{I}}\right)
$$

donde:

CEC - consumo específico de combustível, $\mathrm{g} \mathrm{kW}^{-1} \mathrm{~h}^{-1}$

$\mathrm{M}$ - consumo horário de combustível, $\mathrm{kg} \mathrm{s}^{-1}$

$\mathrm{V}$ - tensão de saída, $\mathrm{V}$

I - corrente elétrica, $\AA$

Outro parâmetro utilizado na avaliação do conjunto motor gerador foi a eficiência da conversão da energia química do combustível em movimento pelo motor, seguido de geração de eletricidade em um gerador monofásico. $O$ cálculo da eficiência do conjunto motor gerador foi realizado com a Eq. 3 .

$$
\eta=\left(\frac{3600}{\mathrm{PCI} \times \mathrm{CEC}}\right) \times 100
$$

sendo:

$\eta$ - eficiência do conjunto, \%

CEC - consumo específico de combustível, $\mathrm{g} \mathrm{kW}^{-1} \mathrm{~h}^{-1}$

$\mathrm{PCI}$ - poder calorífico inferior, $\mathrm{MJ} \mathrm{kg}^{-1}$
Visando determinar o poder calorífico das misturas combustíveis utilizou-se o calorímetro modelo E2K. As amostras das misturas foram separadas em $0,5 \mathrm{~g}$ do combustível analisado. O método para determinar o poder calorífico superior com o calorímetro consiste em pressurizar, com uma bomba, o recipiente adiabático com a amostra, sendo este recipiente acoplado ao fio de ignição. A pressão mantida no calorímetro E2K foi de $30 \mathrm{~atm}$ (3,04 MPa). Os ensaios com combustão incompleta foram desprezados. Deste modo, determinou-se o poder calorífico superior dos combustíveis.

Para mensurar e comparar o valor calórico do biodiesel de frango em proporção variável com o óleo diesel, as amostras dos combustíveis (B0, B20, B40, B60, e B100) foram organizadas em um delineamento experimental de blocos ao acaso, com três repetições, para os combustíveis. O poder calorífico inferior das composições foi determinado pela equação descrita em Volpato et al. (2009) que leva em consideração o poder calorífico superior:

$$
\mathrm{PCI}=\mathrm{PCS}-3,052
$$

em que:

PCS - poder calorífico superior, $\mathrm{MJ} \mathrm{kg}^{-1}$

$\mathrm{PCI}$ - poder calorífico inferior, $\mathrm{MJ} \mathrm{kg}^{-1}$.

\section{RESULTADOS E DISCUSSÃO}

\section{Consumo específico de combustível do conjunto motor gerador}

Estudou-se o desempenho do motor gerador utilizandose as proporções de 0, 20, 40, 60 e $100 \%$ de biodiesel. A Figura 1 mostra o comportamento do CEC do motor em função da variação da carga aplicada ao gerador demonstrando, deste modo, que o CEC é maior quando as cargas são relativamente baixas (menores que 1,5 kW). Utilizando o óleo diesel, o CEC do conjunto motor gerador foi ligeiramente menor, comparado com as misturas com biodiesel B20, B40, B60, B100 (Figura 1).

Segundo Castellanelli et al. (2008) a diferença de viscosidade entre o biodiesel e o óleo diesel também é um fator importante no CEC, causando atomização deficiente e provocando queima incompleta do combustível em regimes de baixas e médias rotações. O torque realizado pelo motor também pode ser utilizado para a avaliação do desempenho do motor. Segundo Volpato et al. (2009) o uso de biodiesel de soja (B100) em um motor diesel é viável mas se verificaram perdas de até $10,7 \%$ no torque e diminuição na potência reduzida de $6,1 \%$, quando comparadas ao funcionamento do motor com o óleo diesel.

Entre as misturas estudadas a que obteve melhor CEC foi B20 (Figura 1A). O resultado mais significativo para este combustível (B20) se deu para a carga nominal de $1,0 \mathrm{~kW}$, em que o CEC - B20 foi 812,25 $\mathrm{g} \mathrm{kW}^{-1} \mathrm{~h}^{-1}, 14 \%$ menor que 943,68 $\mathrm{g} \mathrm{kW}^{-1} \mathrm{~h}^{-1}$, que corresponde ao CEC - B0. Segundo Xue et al. (2011) o CEC do biodiesel é maior, e a redução do CEC é possível quando se reduz o biodiesel na proporção do combustível. Os autores relatam, ainda, que com proporção de biodiesel menor na mistura, o desempenho inferior não será notado durante uma atuação prática do motor. 
A.

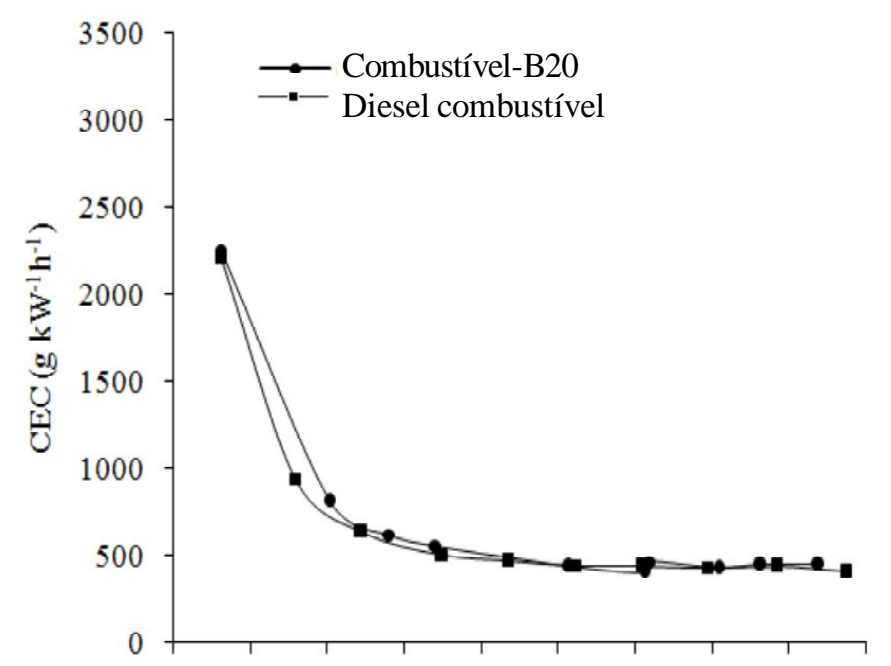

C.

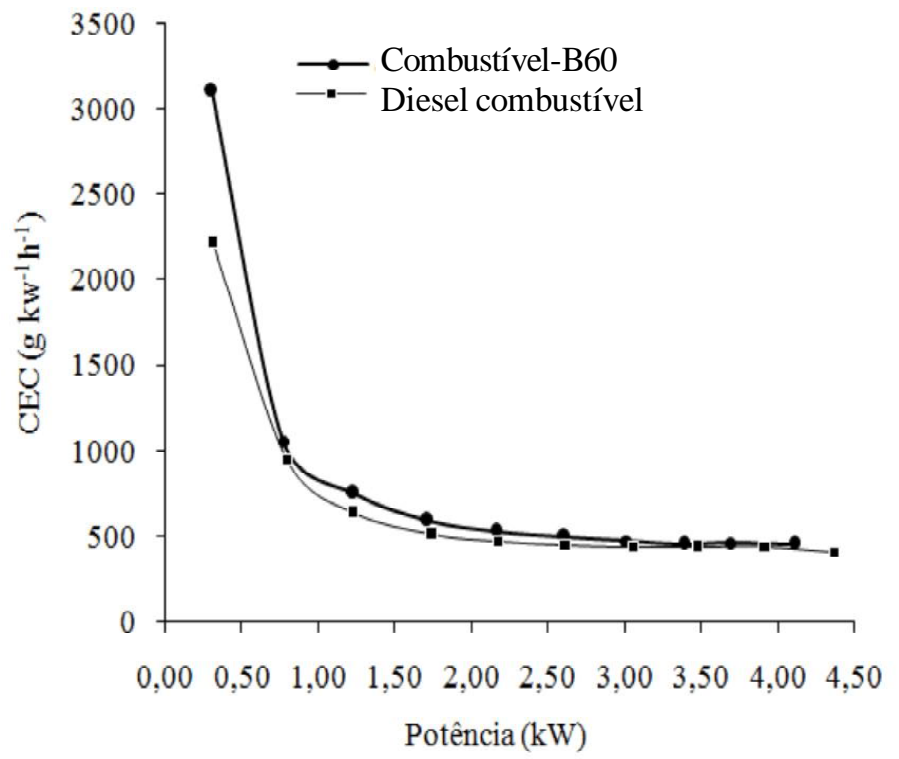

B.

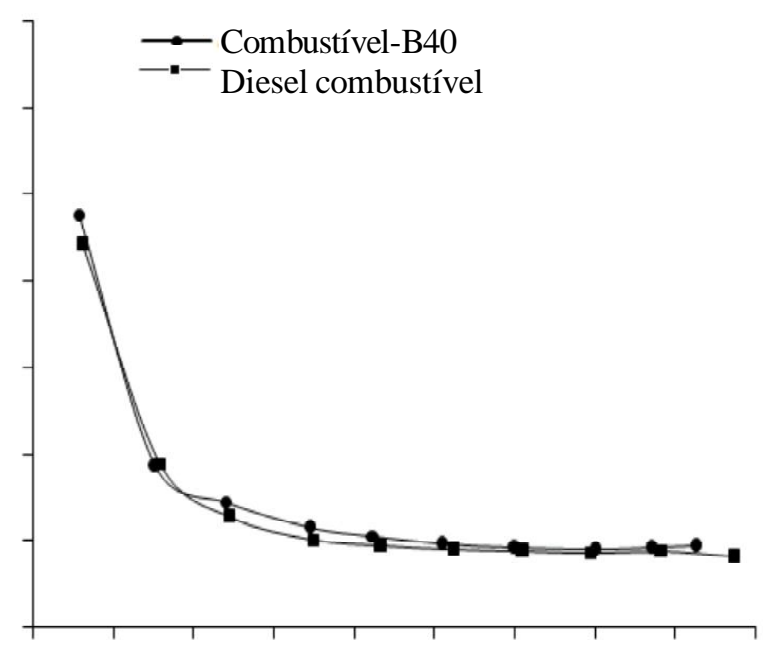

D.

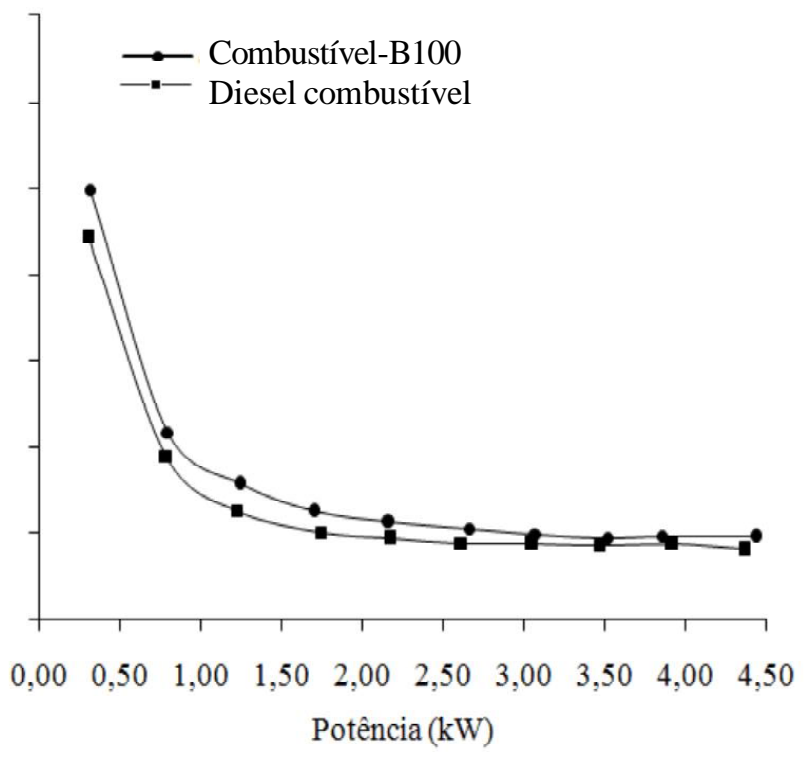

Figura 1. Avaliação do conjunto motor gerador pelo consumo específico de combustível

De acordo com a Figura 1D o desempenho pior se deu para a proporção de $100 \%$ de biodiesel. O resultado mais significativo para este combustível (B100) foi para a carga nominal de 1,5 $\mathrm{kW}$ cujo CEC - B100 foi 781,85 $\mathrm{g} \mathrm{kW}^{-1} \mathrm{~h}^{-1}$ sendo $23 \%$ maior que CEC - B0 igual a $634,01 \mathrm{~g} \mathrm{~kW}^{-1} \mathrm{~h}^{-1}$. Soranso et al. (2008), obtiveram resultado semelhante quando avaliaram o desempenho dinâmico de um trator agrícola utilizando biodiesel destilado de óleo residual, constatando aumento do consumo específico com as maiores porcentagens de biodiesel na mistura; no entanto, Tabile et al. (2009) obtiveram diferença de CEC maior ao avaliarem o desempenho operacional de um motor utilizando, como parâmetro, a relação de consumo de combustível e constataram, no estudo, que não houve diferença significativa até a proporção de B25; todavia, comparando B0 a B100, o consumo aumentou 38,3\% do combustível.

Os resultados do CEC também foram comparados pela média verificando-se, então, um aumento médio no CEC utilizandose os combustíveis B40, B60 e B100 comparados com o CEC B0 (Figura 2). A única composição com biodiesel na qual não houve, em média, diferença, foi a B20. Nota-se, ainda na Figura 2, que a diferença no CEC aumenta quando a proporção de biodiesel é maior mesmo que em B100 a diferença tenha sido, em média, $16 \%$ maior com comparação com o CEC quando se utilizou o óleo diesel. Soranso et al. (2008) obtiveram, comparando o desempenho do motor utilizando óleo diesel ou biodiesel, um aumento médio de $18 \%$ no CEC quando o combustível foi $100 \%$ biodiesel, semelhante ao obtido neste estudo.

Em um estudo no qual foi utilizado biodiesel Corrêa et al. (2008) compuseram uma mistura volumétrica entre biodiesel produzido do óleo de girassol e óleo diesel nas proporções de B0, B5, B10, B20 e B100, avaliada pelo CEC do motor de um trator cuja tomada de potência foi ligada (TDP) a um dinamômetro, tendo-se obtido, na rotação padrão da TDP (540 RPM), um aumento no CEC não maior que 7,3\% em comparação com o CEC - B0, ou seja, menos da metade do aumento no consumo específico utilizando-se o biodiesel da gordura de frango. 


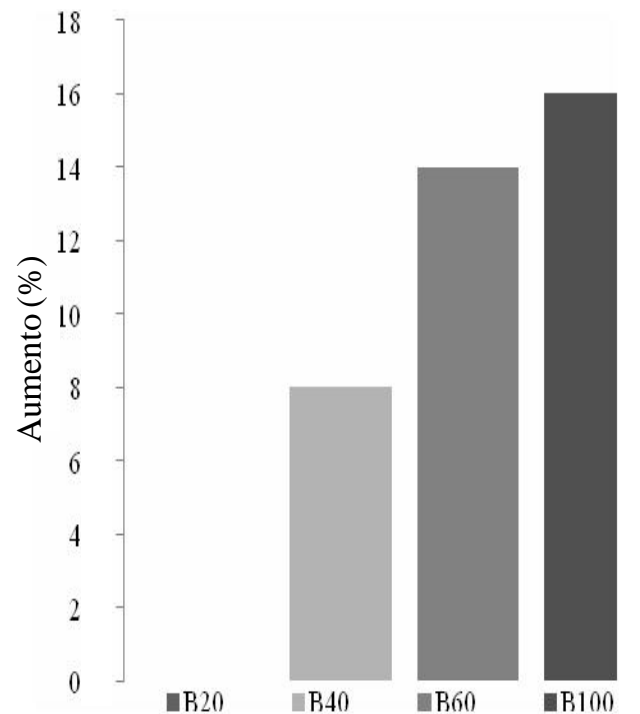

Figura 2. Proporções de biodiesel comparados com 0 CEC-BO

\section{Valor calórico do óleo diesel e biodiesel da gordura de frango}

A Tabela 1 apresenta o poder calorífico superior das cinco misturas realizadas com o biodiesel e óleo diesel. Como método de análise dos valores utilizou-se o teste de comparação de médias. Deste modo, o poder calorífico superior do óleo diesel $\left(44,351 \mathrm{MJ} \mathrm{kg}^{-1}\right)$, B20 (43,666 MJ kg-1) e B40 (42,347 $\left.\mathrm{MJ} \mathrm{kg}^{-1}\right)$ foi considerado semelhante estatisticamente, a nível de $5 \%$ de significância. Os valores do poder calorífico superior das misturas B40 (42,347 $\left.\mathrm{MJ} \mathrm{kg}^{-1}\right)$ e B60 (41,120 $\left.\mathrm{MJ} \mathrm{kg}^{-1}\right)$ também são semelhantes perante a comparação de médias. Com o poder calorífico superior dos combustíveis mensurados, o poder calorífico do óleo diesel (B0) foi 13,32\% maior que o poder calorífico do biodiesel produzido da gordura de frango (B100). Bonometo (2009) levantou o poder calorífico superior do biodiesel da gordura de frango (B100) em um calorímetro e obteve o valor de 42,53 $\mathrm{MJ} \mathrm{kg}^{-1}$, que é superior ao valor obtido por este estudo (Tabela 1).

Tabela 1. Poder calorífico superior das misturas combustível

\begin{tabular}{lcccc}
\hline Diesel/ & \multicolumn{4}{c}{ Amostras (MJ kg $\mathbf{~}^{-1}$ ) } \\
\cline { 2 - 5 } Biodiesel & $\mathbf{1}$ & $\mathbf{2}$ & $\mathbf{3}$ & Média* \\
B0 & 43,834 & 43,496 & 45,273 & $44,351 \mathrm{a}$ \\
B20 & 44,166 & 43,637 & 43,195 & $43,666 \mathrm{a}$ \\
B40 & 42,704 & 41,975 & 42,363 & $42,347 \mathrm{ab}$ \\
B60 & 40,188 & 41,759 & 41,414 & $41,120 \mathrm{~b}$ \\
B100 & 38,134 & 39,718 & 37,468 & $38,440 \mathrm{c}$ \\
\hline
\end{tabular}

* Médias seguidas da mesma letra não diferem significativamente pelo teste de Tukey a nível de $5 \%$

A correção dos valores do poder calorífico superior (PCS) para poder calorífico inferior (PCI) resultou em 41,30 $\mathrm{MJ} \mathrm{kg}^{-1}$ para B0; 40,61 MJ kg-1 para B20 e 39,30 $\mathrm{MJ} \mathrm{kg}^{-1}$ para B40; 38,07 $\mathrm{MJ} \mathrm{kg}^{-1}$ para B60; e 35,39 $\mathrm{MJ} \mathrm{kg}^{-1}$ para B100. O poder calorífico inferior do óleo diesel (41,30 $\left.\mathrm{MJ} \mathrm{kg}^{-1}\right)$ estimado, mostrou-se semelhante ao resultado de 42,90 $\mathrm{MJ} \mathrm{kg}^{-1}$ obtido por Bridgwater et al. (1999). Em estudo de caracterização do óleo diesel e biodiesel, Costa Neto et al. (2000) verificaram que o poder calorífico inferior medido para o óleo diesel foi 42,30 $\mathrm{MJ} \mathrm{kg}^{-1} \mathrm{e}$ para o biodiesel de óleo de soja utilizado em frituras foi de $37,50 \mathrm{MJ} \mathrm{kg}^{-1}$. Para o poder calorífico inferior do biodiesel (B100), chegou-se ao resultado de $35,39 \mathrm{MJ} \mathrm{kg}^{-1}$.

A Figura 3 mostra que o poder calorífico superior reduz-se linearmente com o aumento na porcentagem de biodiesel na mistura. O coeficiente de regressão linear $\left(R^{2}\right)$ obtido na equação é 0,98 , sinal de que o modelo da equação está adequado para estimar valores intermediários aos testes realizados com o biodiesel da gordura de frango e óleo diesel. A equação obtida com a regressão linear foi:

$$
\mathrm{PCS}=44,61-\frac{5,781 \mathrm{~B}_{\mathrm{x}}}{100}
$$

donde:

PCS - poder calorífico superior, $\mathrm{MJ} \mathrm{kg}^{-1}$

$\mathrm{B}_{\mathrm{x}}$ - proporção de biodiesel da gordura de frango, \%

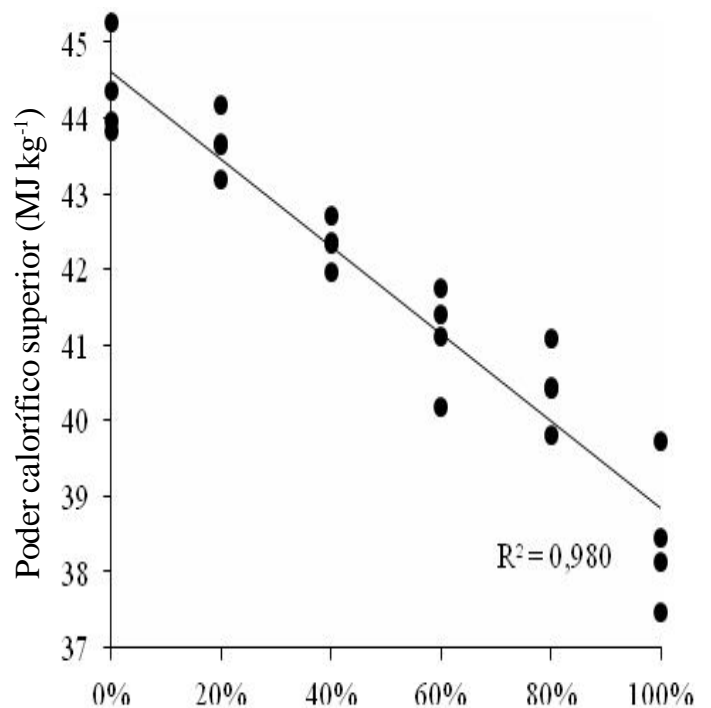

Figura 3. Porcentagens de biodiesel na mistura volumétrica com óleo Diesel

\section{Eficiência do conjunto motor gerador}

A Figura 4 mostra a eficiência e as curvas de tendência numa faixa de carga $(0,5$ a $4,5 \mathrm{~kW}$ de potência nominal) do conjunto motor gerador. Nesta figura se observa que sob cargas menores que $1,5 \mathrm{~kW}$ a eficiência do conjunto foi menor que $15 \%$. Nesta faixa de variação de carga $(0,5$ a $1,5 \mathrm{~kW}$ de potência nominal) o motor tem um CEC maior; entendeu-se, portanto, que quanto maior o CEC, que é variável em função da carga, menor será a eficiência.

A eficiência na conversão da energia química do combustível em energia elétrica no conjunto motor gerador foi medida para as cinco proporções de mistura de biodiesel (Figura 4). O máximo de eficiência obtida para o conjunto foi $22 \%$, operando com a carga efetiva de $4,36 \mathrm{~kW}$ e utilizando óleo diesel. O melhor resultado de eficiência do conjunto motor gerador para as misturas com biodiesel foi utilizando a mistura B20, obtendose $22 \%$ operando com a carga efetiva de $3,10 \mathrm{~kW}$. Quando o conjunto utilizou as misturas combustíveis B40, B60 e B100 foram obtidos até $21 \%$ de eficiência. 
A.

B.
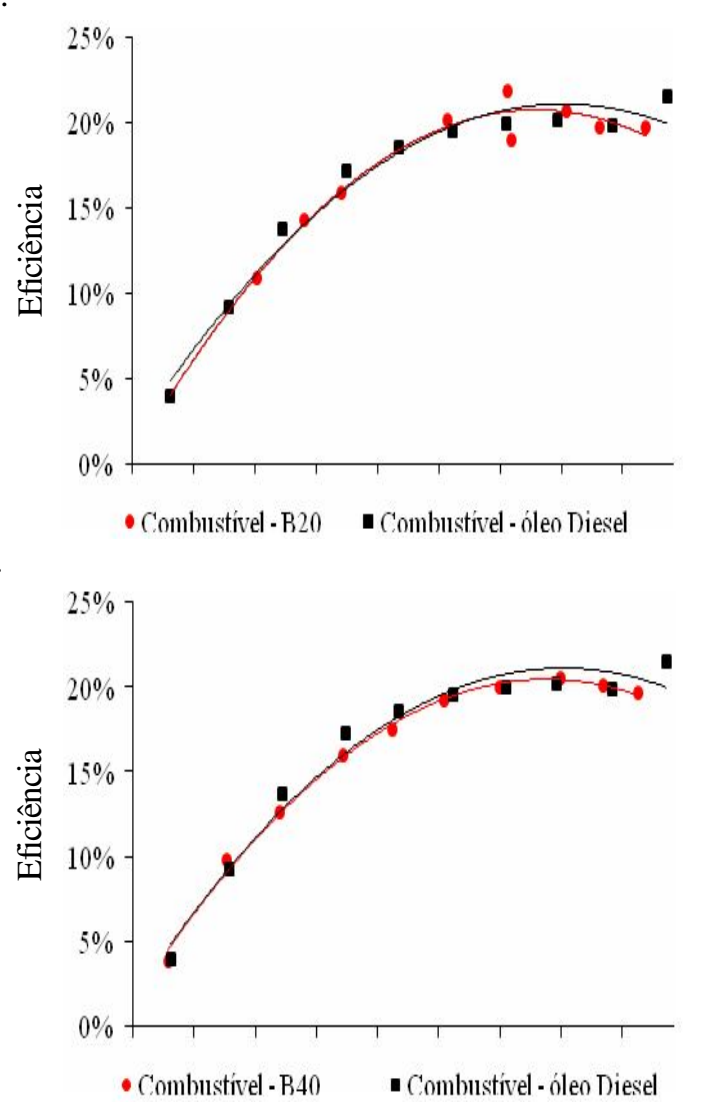

C.

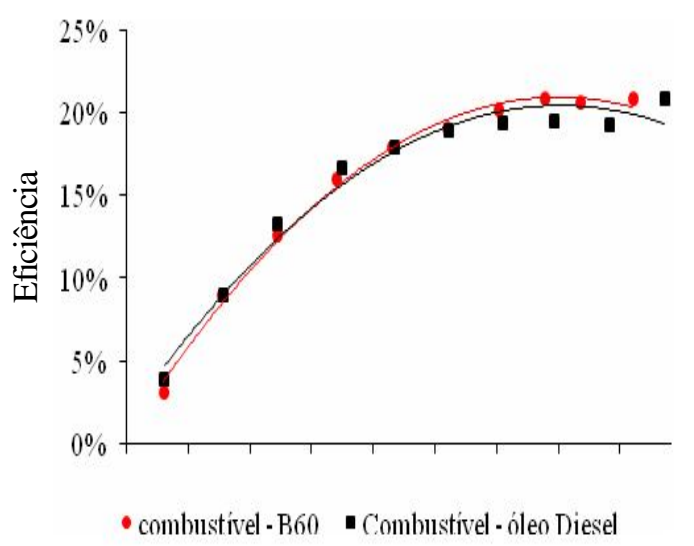

D.

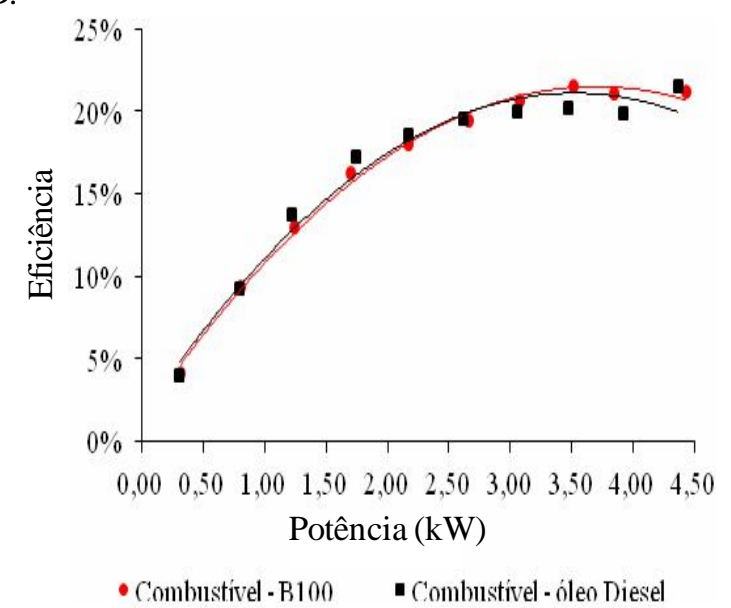

Figura 4. Eficiência do conjunto do conjunto motor gerador
Agarwal \& Das (2001) realizaram ensaios em um motor de combustão interna utilizando onze proporções de biodiesel e óleo diesel (B0, B5, B10, B15, B20, B25, B30, B40, B50, B75 e $\mathrm{B} 100)$. No estudo, foram avaliados o CEC e a eficiência térmica do motor e os resultados comparados com o óleo diesel (B0). Deste modo, os autores verificaram que o melhor desempenho para as misturas combustíveis foi obtido com $20 \%$ de biodiesel, com ganhos de até $2,5 \%$ na eficiência térmica. Barbosa et al. (2008) obtiveram, em média, ganho de $4 \%$ na eficiência do motor ciclo diesel de 58,2 $\mathrm{kW}(78 \mathrm{cv})$ de um trator ao utilizar $100 \%$ de biodiesel, comparando-se com o diesel mineral.

Pode-se observar, na Figura 4, que o comportamento da eficiência do conjunto motor gerador utilizando-se diferentes proporções de óleo diesel com biodiesel, seguiu tendência semelhante. A eficiência do conjunto utilizando a proporção de mistura B20 apresentou resultados semelhantes aos do conjunto em que foi utilizado o diesel mineral (Figura 4A). Mesmo com a eficiência do biodiesel menor (B100, Figura 4D), a diferença da eficiência do conjunto motor gerador com as proporções de biodiesel na mistura (B20, B40, B60, B100) com o diesel mineral (B0), não ultrapassou o valor de $3 \%$ para qualquer uma das cargas nominais.

O desempenho do motor gerador com os combustíveis B60 e B100 foi inferior para o CEC (Figuras 1C e 1D) e valor calórico (Tabela 1) com relação às outras proporções com quantidade menor de biodiesel e para o óleo diesel mineral. Apesar disto, constatouse que a eficiência do conjunto motor gerador utilizando os combustíveis B60 e B100 (Figura 4C e4D), se manteve semelhante aos resultados obtidos com outros combustíveis.

\section{CONCLUSÕES}

1. O desempenho do conjunto motor gerador foi superior quando acionado a óleo diesel; no entanto, a proporção com $20 \%$ de biodiesel no combustível substitui parcialmente o óleo diesel, sem perdas significativas de desempenho do motor em consumo específico de combustível, eficiência ou valor calórico do combustível.

2. O combustível óleo diesel possui valor calórico maior que o biodiesel. A mistura do óleo diesel com biodiesel apresentou redução linear do poder calorífico, descrita em uma equação.

3. O comportamento do motor gerador de $5,5 \mathrm{~kW}$ de potência operando em cargas baixas (menor que $1,5 \mathrm{~kW}$ ) apresentou consumo específico de combustível elevado e, deste modo, o desempenho foi menor, provocando redução na eficiência (menor que 15\%). Sob cargas maiores o desempenho foi superior com o consumo específico de combustível menor (variando menos) e com máximo de eficiência de 19 a $21 \%$ para o conjunto motor gerador.

\section{LITERATURA CITADA}

Agarwal, A. K.; Das, L. M. Biodiesel development and characterization for use as a fuel in compression ignition engines. Journal of Engineering for Gas Turbines and Power, v.123, p.440-447, 2001. 
Bonometo, R. P. Análise energética do processo experimental de produção de biodiesel a partir de óleo de frango. Botucatu: UNESP, 2009. 45p. Dissertação Mestrado

Bridgwater, A. V.; Meier, D.; Radlein, D. An overview of fast pyrolysis of biomass. Organic Geochemistry, v.30, p.14791493, 1999.

Barbosa, R. L.; Silva, F. M.; Salvador, N.; Volpato, C. E. S. Desempenho comparativo de um motor de ciclo diesel utilizando diesel e misturas de biodiesel. Revista Ciência e Agrotecnologia, v.32, p.1588-1593, 2008.

Castellanelli, M.; Souza, S. N. M.; Silva, S. L.; Kailer, E. K. Desempenho de motor ciclo Diesel em bancada dinamométrica utilizando misturas diesel/biodiesel. Engenharia Agrícola, v.28, p.145-153, 2008.

Corrêa, I. M.; Maziero, J. V. G.; Storino, M. Mistura de biodiesel de sebo bovino em motor diesel durante 600 horas. Ciência Rural, v.41, p.1189-1194, 2011.

Corrêa, I. M.; Maziero, J. V. G.; Úngaro, M. R.; Bernardi, J. A.; Storino, M. Desempenho de motor diesel com misturas de biodiesel de óleo de girassol. Revista Ciência Agrotecnologia, v.32, p.923-928, 2008.

Costa Neto, P. R.; Rossi, L. F. S.; Zagonel, G. F.; Ramos, L. P. Produção de biocombustível alternativo ao óleo diesel através da transesterificação de óleo de soja usado em frituras. Química Nova, v.20, p.532-537, 2000.

Dabdoub, M. J.; Bronzel, J. L.; Rampin, M. A. Biodiesel: visão crítica do status atual e perspectivas na academia e na indústria. Química Nova, v.32, p.776-792, 2009.
IBGE - Instituto Brasileiro de Geografia e Estatística. Estatística da produção pecuária - indicadores IBGE. Brasília: Governo Federal. 2010. 22p.

Gomes, L. F. S.; Souza, S. N. M.; Baricatti, R. A. Biodiesel produzido com óleo de frango. Revista Acta Scientiarum Technology, v.30, p.57-62, 2008

Knothe, G.; Gerpen, J. V.; Krahl, J.; Ramos, L. P. Manual de biodiesel. 1.ed. São Paulo: Edgard Blücher, 2006. 340p.

Kulkarni, M. G.; Dalai, A. K. Waste cooking oil - an economical source for biodiesel: a review. Industrial \& Engineering Chemistry Research, v.45, p.2901-2913, 2006.

Soranso, A. M.; Gabriel Filho, A.; Lopes, A.; Souza, E. G.; Dabdob, M. J.; Furlani, C. E. A.; Camara, F. T. Desempenho dinâmico de um trator agrícola utilizando biodiesel destilado de óleo residual. Revista Brasileira de Engenharia Agrícola e Ambiental, v.12, p.553-559, 2008.

Tabile, R. A.; Lopes, A.; Dabdoub, M. J.; Câmara, F. T.; Furlani, C. E. A.; Silva, R. P. S. Biodiesel de mamona no diesel interior e metropolitano em trator agrícola. Engenharia Agrícola, v.29, p.412-423, 2009.

Volpato, C. E. S.; Conde, A. P.; Barbosa, J. A.; Salvador, N. Desempenho de motor diesel quatro tempos alimentado com biodiesel de óleo de soja (B 100). Revista Ciência Agrotecnológica, v.33, p.1125-1130, 2009.

Xue, J.; Grift, T. E.; Hansen, A. C. Effect of biodiesel on engine performances and emissions. Renewable and Sustainable Energy Reviews, v.15, p.1098-1116, 2011. 